\title{
Re-inventando islas coloniales en un contexto transimperial: “Abdala" (1869), de José Martí y Las errancias de Oisin (1889), de W. B. Yeats ${ }^{1}$
}

\author{
Kevin Sedeño-Guillén ${ }^{2}$ \\ Colorado College (Estados Unidos) / \\ Universidad de Cartagena (Colombia) \\ ORCID ID: 0000-0002-0940-8198 \\ Recibido: 10 de abril de 2019 \\ Aceptado: 2 de julio de 2019
}

\section{RESUMEN}

Este artículo propone una lectura comparada de "Abdala" (1869), de José Martí (1853-1895) y Las errancias de Oisin (1889), de William Butler Yeats (1865-1939), que explica cómo las marcas simbólicas asociadas con imaginarios insulares y las convergentes condiciones de confrontación nacionalista y/o independentista subyacen en las textualidades de estos poemas, articulando de manera inextricable la condición insular y la condición colonial. Ello desplazaría a estos textos a un ámbito transimperial, translingüístico y profundamente atravesado por representaciones transatlánticas de lo insular. Se concluye que en "Abdala” se produce un desplazamiento espacial, en el que se traslada el escenario de su representación de la isla caribeña a una nación africana, mientras que en Las errancias de Oisin el desplazamiento se produce en el eje temporal, remontándose a los orígenes míticos de la nación irlandesa. Tanto "Abdala" como Las errancias de Oisin constituyen, de ese modo, poemas postcoloniales que dan cuenta de desplazamientos espaciales y temporales que funcionan como estrategias para burlar la vigilancia y control colonial de sus respectivas metrópolis.

Palabras clave: José Martí, “Abdala”, William Butler Yeats, Las errancias de Oisin, estudios insulares

\begin{abstract}
This article proposes a comparative reading of "Abdala" (1869), by José Martí (1853-1895) and The Wanderings of Oisin (1889), by William Butler Yeats (1865-1939). The analysis seeks an explanation for the way in which symbolic traces associated with island imaginary, and the convergent conditions of nationalist and/or independent confrontations informinforms the textualities of both poems. In this way, an island condition and a colonial condition are shown as inextricably associated. As a result, these texts are displaced to a transimperial and translinguistic space, profoundly traversed by transatlantic representations of island. The conclusions indicate

\footnotetext{
${ }^{1}$ Re-inventing Colonial Islands in a Transimperial Context: José Martís “Abdala” (1869) and W. B. Yeats's The Wanderings of Oisin (1889) ${ }^{2}$ Doctor en Estudios Hispánicos, University of Kentucky. Profesor asistente visitante, Department of Spanish and Portuguese, Colorado College. Profesor del Programa de Lingüística y Literatura, Universidad de Cartagena. Correo electrónico: kevin.sedeno-guillen@uky.edu
} 
a space displacement produced in "Abdala", with the translation of its scenario from the Caribbean island to an African nation. Meanwhile, in The Wanderings of Oisin, this displacement is produced in the temporal axis, going back to the mythical origins of the Irish nation. Both "Abdala" as well as The Wanderings of Oisin are configured as postcolonial poems that show spatial and temporal displacements with the intention of escaping colonial surveillance and control by their respective metropolis.

Keywords: José Martí, “Abdala”, William Butler Yeats, “The Wanderings of Oisin”, island studies

Creo necesario iniciar este estudio argumentando las razones/intuiciones en las que me baso para relacionar dos poemas dramáticos escritos en la segunda mitad del siglo XIX, uno por un súbdito colonial español e hispanohablante, el cubano José Martí (1853-1895), y el otro por el irlandés William Butler Yeats (1865-1939), habitante de un país sometido al colonialismo inglés y, debido a eso, angloparlante él mismo. Sin embargo, detrás de estas aparentes divergencias de localización geográfica y de lenguas, emergen regularidades que me servirán como condiciones de posibilidad de la lectura en simultáneo que emprendo aquí. Me refiero a la semejanza espacial entre Martí y Yeats como sujetos insulares. Ambos, más allá del hecho de haber nacido en territorios insulares, experimentan significativamente en su escritura los particulares contextos geopolíticos de las islas colonizadas que habitan.

La comprensión de la circunstancialidad de los referidos contextos gana en capacidad explicativa cuando se contrasta con el imaginario sobre las islas producido, acumulado y propulsado en/desde Europa en un amplio lapso temporal que se extiende al menos desde el denominado periodo medieval temprano hasta la actualidad. Asumo la representación de las islas globales en el imaginario occidental como una estrategia de otrificación de las culturas insulares, que debe ser restablecida en su función dominante dentro de los mecanismos de expansión europea al resto del mundo. Bajo esta premisa, emprendo entonces una lectura comparativa de "Abdala" (1869), de Martí, y The Wanderings of Oisin [Las errancias de Oisin] (1889), de Yeats, buscando avanzar en la formulación de una explicación acerca de cómo las marcas simbólicas asociadas con imaginarios insulares

y las condiciones de confrontación nacionalista y/o independentista contribuyen a la comprensión de sus textualidades, articulando de manera inextricable la condición insular y la condición colonial, lo que desplazaría a estos textos a un ámbito transimperial, translingüístico y profundamente atravesado por imaginarios insulares transatlánticos.

\section{La perspectiva de los estudios insulares}

Los debates que expondré a continuación se conectan con un campo transdisciplinar en formación que se dedica al estudio de las islas desde sí mismas. Este campo ha sido denominado tempranamente como nissology (nisología) (Moles, 1982; Depraetere, 1990-1991, 2008 y McCall, 1994, 1996), principalmente desde las enunciaciones de académicos de las ciencias naturales y sociales (Campomanes, 2018: s.p.). Según estas perspectivas, la nisología constituye un discurso retórico 
y subalterno de los habitantes de islas, que funciona por igual como esfuerzo de comprensión de las islas como tal (McCall, 1996: 1). Mientras, nesologies (nesologías) -en plural-sería el término preferido desde la tradición de las humanidades (Campomanes, 2018: s.p.). Según aduce Antonis Balasopoulos, esta opción se explica porque el término "nesologías" concerniría simultáneamente tanto al registro estético como al geopolítico de la imagen de la isla, y no sólo a la aproximación empírica a la insularidad, como sería el caso de la nisología (Balasopoulos, 2008: 24, n. 4). ${ }^{3}$ No resulta difícil aceptar que los debates nominativos mencionados han convergido en el campo interdisciplinario de los island studies (estudios insulares). A favor de esta idea, Godfrey Baldacchino plantea, en una primera aproximación, que 'Explaining 'island studies' as the critical, inter- and pluri-disciplinary study of islands on their own terms is perhaps an elegant explanation, but still somewhat cryptic" (Baldacchino, 2006: 10). Sin embargo, el propio carácter inter o transdisciplinario de los estudios insulares complica la posibilidad de su propia definición, objetivo que tampoco vamos a emprender en este artículo. ${ }^{4}$ Baste con señalar que amplias zonas teóricas, críticas y metodológicas de la academia euro-norteamericana implicadas en el estudio de las islas, terminan convergiendo con aquellas representaciones exteriores sobre las propias islas que se han propuesto superar.

En este contexto, conviene sin embargo retomar una afirmación de Edward Said que conecta la pregunta acerca de lo espacial -y en específico de lo insular- con la cuestión colonial. En su texto "Yeats y la descolonización", que hace parte de su libro Culture and Imperialism (1993) afirma que

Si existe algo que distingue radicalmente la imaginación antiimperialista, es la primacía que tiene en ella el elemento geográfico. Después de todo, el imperialismo es un acto de violencia geográfica por medio del cual, virtualmente, cualquier espacio del globo es explorado, cartografiado y finalmente sometido a control. Para el nativo, la historia de la servidumbre colonial comienza con la pérdida del lugar a favor del extraño: más adelante se buscará e intentará restaurar la identidad geográfica perdida. A causa de la presencia del extraño colonizador, la tierra será primero recuperada sólo en el plano de la imaginación (Said, 1996: 349).

Esta precisión de Said acerca del carácter constitutivo de la relación entre imperialismo y "violencia geográfica" establece -en mi criterio- un estrecho vínculo epistemológico entre los estudios insulares y los estudios poscoloniales. Si la recuperación imaginaria de lo geográfico fue una de las primeras estrategias de los poetas poscoloniales, sería reconstruyendo los mapas de esos desplazamientos espaciales como podríamos retomar la particular comprensión simbólico-política de los espacios insulares emprendida individualmente, en la segunda mitad del siglo XIX, por

\footnotetext{
${ }^{3}$ Debo recordar que ambos términos, nisología y nesología, apelan respectivamente a las raíces griegas para "isla": nisos o nesos, según sea la variante ortográfica que se prefiera. Otros términos más o menos afortunados críticamente, que han sido propuestos para denominar el campo de estudio de las islas son: "nissonologie" (Moles, 1982), "nesologies", "islandology" (Shell, 2014).

${ }^{4}$ Para profundizar en los aspectos teóricos, críticos y metodológicos de los estudios insulares, y de otros ámbitos disciplinares cuyo objeto de estudio ha sido la representación de las islas, véase mi introducción a este número monográfico "Islas (des)imaginadas: de la matriz moderno-colonial al Caribe archipelágico" (Sedeño).
} 
Martí y Yeats. Esta conjunción entre lo insular y lo colonial permite conectar territorios incluidos en amplias y dispersas geografías vinculadas a los colonialismos español e inglés, lo cual facilitaría el análisis de ciertas zonas de la experiencia colonial cubana e irlandesa a través del estudio comparado de la poesía de Martí y Yeats. Al respecto, argumenta Jahan Ramazani que la crítica poscolonial

[...] provides a comparative framework more bounded and historical than "world poetry" but less restrictive than "national" or "regional" poetry. Although the terms "postcolonial", "Third World," and "non-Western" have often been criticized for erasing cultural and historical differences among various cultures still grappling with their colonial histories (Ramazani, 2001: 4).

Ramazani señala, de forma más específica en relación con Yeats, que

Exploring the controversial question of whether Yeats should be read as a postcolonial poet, I discuss this liminal example to reexamine some of the major concepts through which postcoloniality has been defined and debated: after colonialism, anticolonialism, nationalism, the Third World, and hybridity(5). ${ }^{5}$

En una etapa inicial de su reflexión sobre lo poscolonial, Walter Mignolo contendía aún con una puesta en relación entre la experiencia poscolonial y la situación latinoamericana y caribeña. En el contexto de ese debate afirmaba que

José Martí was a postcolonial Caribbean intellectual, in today’s sense of "postcolonial." To "decolonize" at the beginning of the nineteenth century, when being free of the Spanish or the Portuguese monarch meant falling into the hands of the British or the French Empire, was a different experience from the decolonizing movements which took place after World War II" (Mignolo, 1995: 207).

Sin embargo, en un momento posterior, Enrique Dussel, Silvia Rivera Cusicanqui y Walter Mignolo, entre otros intelectuales latinoamericanos, propusieron que si la perspectiva poscolonial da cuenta de la crisis de la modernidad tal como se experimentó en la India y otras colonias inglesas, el posoccidentalismo sería la forma en que desde América Latina y el Caribe se manifestó de forma particular este proceso (Mignolo, 1998). Esto explica el porqué del giro desde la perspectiva poscolonial a la posoccidental, en la comprensión de la experiencia colonial del Caribe hispanoparlante, especialmente en la experiencia política y poética de José Martí.

\footnotetext{
${ }^{5}$ La incorporación de Yeats al canon poscolonial no se ha producido sin enconados debates. Para Ramazani, el decidir sobre la pertenencia o no de Yeats a este grupo implicaría analizar que, si una primera acepción del prefijo "post" se referiría a "después del" colonialismo, habría entonces que considerar que su más tardía poesía sería poscolonial, mientras que la temprana sería colonial. Pero, considerando que la poesía tardía se manifiesta muchas veces permeada de escepticismo político mientras que la temprana es explícitamente nacionalista, la anterior definición de "post" se mostraría inoperante. A ese respecto concluye que varios escritores considerados indiscutiblemente como poscoloniales publicaron trabajos considerados como poscoloniales antes de la independencia: "[...] since if post means being free from the colonizer's cultural marks and deposits, no anglophone writing is entirely postcolonial. If postcoloniality is construed not as 'after decolonization' but as 'since colonization,' then Yeats is more easily swept whole into the postcolonial canon [...]" (Ramazani, 1998: 67).
} 
Como cierre para esta sección, resulta conveniente retomar la propuesta teórico-metodológica de la imposibilidad de aislar el estudio de las islas de los procesos de expansión imperial europea hacia el resto del mundo. En esa dirección, afirma Pete Hay que

The island itself is seen to be a post-colonial trope, one traceable to Eurocentric assumptions of dominance, and only recently challenged by those with a capacity to see past the screens and obfuscations. Furthermore, those constructions of islandness that stress identity, uniqueness and home are seen to partake of the persistence of post-colonialism, being wedded to outmoded values that take no cognizance of a postmodern fluidity in which endless change rather than enduring identities is the signature, and, thus, to be part of the problem rather than the solution. (Hay, 2006: 28).

La noción de isla como representación predominante, posible sólo dentro de la lógica de los discursos coloniales, como "tropo postcolonial" que reproduce la "violencia geográfica" del imperialismo y el colonialismo, reaparecerá recurrentemente en los análisis que siguen en este artículo.

\section{Lapsus insular: desplazamiento espacial y camuflaje en "Abdala” de José Martí}

El 23 de enero de 1869, José Martí (1853-1895) publica en La Habana, en el número único del periódico La Patria Libre: semanario democrático-cosmopolita, su temprano poema dramático "Abdala". Los protagonistas del poema son Abdala, un príncipe y guerrero nubio, su madre Espirta y su hermana Elmira. Por su parte, su argumento remite a la llegada de un "feroz conquistador" extranjero que amenaza la independencia de Nubia y que obliga a Abdala a colocarse al frente de su ejército, contra el deseo de su madre, provocando al desenlace trágico del poema. " "Abdala" ha sido generalmente leído como una alegoría política, de "carácter patriótico-simbólico y elevado tono épico" (Gutiérrez de la Solana, 1978: 17), referida a las circunstancias de la crisis del sistema colonial español en Cuba, durante el último cuarto del siglo XIX. Esta interpretación se basa en que, en octubre de 1868, tan sólo tres meses antes de la publicación de "Abdala", había estallado en el oriente de la Isla una insurrección armada, comandada por Carlos Manuel de Céspedes, que sería luego conocida como la Guerra de los 10 años. Estos hechos llevarían al recrudecimiento de la censura de prensa por parte de las autoridades españolas en la Isla, una de las últimas posesiones coloniales de España en las Américas.

No obstante, mi línea actual de interpretación de "Abdala" se desplaza hacia una zona conexa en que convergen lo histórico colonial y lo geopoético. Me interesa especialmente concentrarme en la decisión de Martí de trasladar el escenario de su drama de la isla caribeña en la que ocurren los conflictos armados que él pretende representar, a la geografía histórica del remoto reino africano

\footnotetext{
${ }^{6}$ Presenté una versión abreviada de esta sección como ponencia en el panel "Islas imaginadas como artefactos ideológicos de la expansión europea”, que organicé en el XIV Seminario Internacional de Estudios del Caribe. Cartagena de Indias: Instituto Internacional de Estudios del Caribe, Universidad de Cartagena, jul. 30 - ago. 2, 2019.

${ }^{7}$ Como es ampliamente conocido, Nubia fue un antiguo reino del norte de África, localizado entre Egipto y Sudán, en una franja de territorio con fronteras en el río Nilo y el mar Rojo, que en ciertos períodos históricos tardíos coincidió parcialmente con Etiopía. Para el momento en que Martí escribe su poema, inspirado en el antiguo valor de los guerreros nubios, ya Nubia había sucumbido a la conquista en 1821 de Mohamed Ali Pasha, gobernante turco-otomano de Egipto.
} 
de Nubia. La decisión geopoética de Martí de trasladar Cuba a Nubia no resulta excéntrica en lo absoluto a amplias zonas del pensamiento occidental -al menos desde la segunda mitad del siglo XVIII- donde se producen las más disímiles representaciones de Nubia y otros territorios asimilados económica, política y simbólicamente como consecuencia de la expansión colonial europea a África. ${ }^{8}$ Estas visiones han sido descritas como manifestaciones orientalistas asociadas, en este caso, con el modernismo hispanoamericano, lo que haría de "Abdala" un "drama oriental" (Azougarh, 1998: 16).

Aunque, contradictoriamente, cuanto más el texto de "Abdala" se transfiere a la geografía continental de Nubia, más insiste en aparentar el vacío de la propia insularidad de Cuba. ${ }^{9}$ Es precisamente en estas tácticas de analogía, ocultamiento, elipsis o, desplazamiento simbólico del espacio -como refiero en el título de esta sección- donde radica la dificultad interpretativa asociada a la lectura insular/colonial que aquí intento. De ese modo, "Abdala" funciona como un texto dado al ocultamiento al no referir, explícitamente, lo que a los lectores que le son contemporáneos, y aún a los actuales, no les resulta muy difícil de dilucidar. La palabra "isla" no aparece nunca en el poema, tampoco "mar", ni ningún otro término asociado con el campo simbólico insular. Sin embargo, sabemos que la isla está allí, en algún lugar oscuro, aunque no totalmente borrado, del texto; y será necesario localizarla, nombrarla y, en lo posible, reponerla de su lugar silenciado en la interpretación de la geopoética del texto martiano. La primera señal y, quizás la más obvia, del desplazamiento simbólico del espacio que se produce en "Abdala" radica en una de las indicaciones iniciales, que refiere: "La escena pasa en «Nubia»" (Martí, 2016: 13). Esta indicación, con el correspondiente entrecomillado del nombre del lugar donde transcurriría la opción dramática, funciona como un guiño al lector, que indica que el lugar que se indica, "Nubia", al estar entre comillas, no es el lugar verdadero, sino un lugar otro que reemplaza al lugar [Cuba], que no es mencionado.

De inmediato, la "Escena primera" nos informa del peligro de invasión extranjera que amenaza al reino. Sabemos también que la capital del reino, tradicionalmente apartada y protegida por sus murallas, sufre ahora un doble aislamiento representado por las tiendas de los enemigos. Los invasores demandan que se rinda: “[...] fuego y aire, tierra y agua!” (Martí, 2016: 13). La respuesta del héroe Abdala es:

Pues decidle al tirano que en la Nubia

Hay un héroe por veinte de sus lanzas:

Que del aire se atreva a hacerse dueño:

\footnotetext{
${ }^{8}$ Cabría mencionar algunas producciones, de las más diversas disciplinas y géneros como historia, paleografía, historia natural, etc., presentados en forma de obras literarias, pinturas, libros de viajes, libretos musicales, etc., que documentan la "fascinación" occidental hacia la representación de Nubia: el libro Voyage en Éthiopie au Soudan Oriental et dans la Nigritie (1862), de Pierre Trémaux (1818-1895); La Nitteti (1756), opera de Josef Mysliveček (1737-1781), localizada en Egipto y Aida (1871), opera de Giuseppe Verdi (1813-1901), con libreto de Antonio Ghislanzoni (18241893), que también desarrolla su trama en Nubia/Egipto, entre otros.

${ }^{9}$ En el ámbito de la literatura cubana, varios autores antes que Martí se valieron de similar estrategia de desplazamiento de escenarios literarios para burlar la censura. En esta dirección, Carmen Suárez León se refiere a las conexiones establecidas por María Poumier entre la tragedia Abúfar (1795), de Jean-François Ducis y traducida por José María Heredia (1803-1839) en 1826 y “Abdala” (Suárez León, 2004: 6).
} 
Que el fuego a los hogares hace falta:

Que la tierra la compre con su sangre:

Que el agua ha de mezclarse con sus lágrimas (13).

Aunque de forma aún ambigua, en esta escena se introduce el elemento acuático. No es claro, empero, si se trata de agua potable en medio del desierto nubio o de agua salada de sus costas marinas. Sin embargo, Abdala amenaza con convertir el agua, para los enemigos, en lágrimas tan saladas como el agua del mar. El nombre del pueblo invasor no ha sido, sin embargo, anunciado. Feroz conquistador, el enemigo, rudo opresor, extraño, bárbaro tirano. Con todas esas formas lo refiere, pero no aparece en esta escena el gentilicio preciso. Por su parte, en la "Escena segunda" lo líquido deviene sangre: "[...] la sangre corre / Por el llano a torrentes ]...[" (Martí, 2016: 15), formando olas sobre la superficie del campo de batalla. Pero no es hasta la "Escena quinta" donde identifico el nudo de la interpretación que intento articular. En esta escena, Abdala se enfrenta a su madre y se niega a ceder a sus ruegos de que abandone, en nombre de su amor, el propósito de ir a la guerra:

Perdona ¡oh madre! que de ti me aleje

Para partir al campo. ¡Oh! estas lágrimas

Testigos son de mi ansiedad terrible,

Y el huracán que ruge en mis entrañas (Martí, 2016: 17).

La sorpresiva aparición de la voz maya quiché "huracán”, empleada inequívocamente para designar las tormentas tropicales en el Caribe, irrumpe como especie de lapsus o insinuación cuyo resultado es que, consciente o inconscientemente, la filiación caribeña de "Abdala" es revelada. El protagonista del poema apela a esta imagen para referirse a la fuerza que arremolina sus líquidos esenciales: lágrimas y sangre implícita en sus entrañas. La ansiedad insular del poeta, que insiste en ocultar el escenario natural de su relato lírico, lo delata al aludir a un tipo de tormenta tropical inexistente en el ámbito de las arenas de los desiertos nubios. Podría adelantar que, tras la irrupción de ese "huracán" verbal, "Abdala" se revela como un texto menos acerca de Nubia de lo que lo es acerca de Cuba.

Nubia/Cuba es un "rincón de tierra" (Martí, 2016: 18) agredido por un enemigo externo. Sin embargo, el poema nunca menciona el nombre del país agresor, ni real ni supuesto, lo que hace parte de los múltiples desplazamientos espaciales que se dan en su interior. Nubia no es un país colonial que intenta liberarse, sino uno independiente que ve amenazada su soberanía, lo que significa un notable desplazamiento en relación con la situación colonial de Cuba. Tenemos así un pueblo que fue paradigma de libertad y la perdió, simbolizando la gesta de otro que camina hacia la independencia. La patria de Abdala no es una isla, como lo es la de Martí -contrariamente, es un ámbito 
continental-, pues haber optado por la configuración geográfica insular para localizar el poema, habría hecho demasiado evidente a las autoridades coloniales españolas el verdadero sentido de este como exhortación a la guerra contra los colonizadores.

Adicionalmente, cabe destacar la arriesgada clave de interpretación del poema que se encuentra en su ambigua dedicatoria: "Escrito expresamente para La Patria", frase referida por igual al medio de prensa en que se publica el poema, La Patria Libre, como a Cuba como patria (Martí, 2016: 13). En este sentido, es oportuno citar a Ottmar Ette cuando plantea que

La situación insular se puede entender no solamente en el sentido geográfico sino también en el sentido político-cultural de aislamiento, de un vivir sin contactos ni comunicaciones a lo que ya se refirió José Martí y a lo que -todavía cien años después- apunta la constatación acertada de Darcy Ribeiro de que hoy en día los latinoamericanos siguen viviendo como en un archipiélago (Ette, 1986: 138).

Para la mentalidad poscolonial de Martí no debió existir espacio más propicio al simbolismo del aislamiento que la antigua Nubia, ubicada entre desiertos, cataratas y montañas. El hecho de que para la fecha el reino africano había dejado de ser un territorio independiente contribuiría también a dotarla, ante la estrategia simbólico-política martiana, de una intangibilidad propicia al vaciado semántico al que pretendía someterla, para que reemplazara así -en el espacio simbólico- a una isla que no podía ser nombrada y que por tanto era necesario camuflar en el lenguaje, para facilitar su futura existencia independiente en lo político.

El poema disimula el territorio geográfico colonial de la isla de Cuba de finales del siglo XIX por medio de la escenificación de la patria continental y antigua de Nubia. No resulta del todo novedoso afirmar que estos desplazamientos indican la afiliación a un proyecto de conformación de una entidad política nacional independiente. Sin embargo, esa patria y nación que se promueven no son otras que una patria y una nación insular. "Abdala" apunta así a una red de complicidades coloniales que, como analizo a continuación, conecta un momento estertóreo del colonialismo español en las Américas con imaginarios asociados al auge del colonialismo inglés y europeo en general en África.

\section{Las errancias de Oisin (1889): de la isla de mítica a la poscolonial}

William Butler Yeats (1865-1939) fue comisionado en 1887 para preparar dos selecciones de leyendas tradicionales irlandesas. Este trabajo le sirvió para preparar The Wanderings of Oisin (1889) -traducido al español como Las errancias de Oisin-, un poema narrativo largo, de carácter mítico, inspirado en las leyendas celtas, que el connotado líder nacionalista irlandés John O’Leary (18301907) -fundador de Irish Republican Brotherhood y contemporáneo de Yeats (Cowell, 1969: 14)le había urgido escribir y luego se encargó de publicar. ${ }^{10}$ Raymond Cowell considera que el poema

\footnotetext{
${ }^{10}$ Yeats habría basado específicamente el argumento de su poema en la adaptación de Bryan O’Looney del poema gaélico de Michael Comyn titulado “The Lay of Oisin on the Land of Youth", aunque había leído también “Oisin in Tirnanoge”, una popularización de O’Looney, realizada por P. W. Joyce (Unterecker, 1959: 54). Sobre el uso del celtismo en la literatura inglesa véase: Carruthers, 2003.
} 
es fundamentalmente: "[...] a eulogy of the heroic age of Ireland, the time of Finn, the king, his son Oisin, and their followers, the Fianna. Contrasted contemptuously with these heroes are Saint Patrick and his followers, who have produced an age of petty restrictions and caution" (Cowell, 1969: 15-16). Sin embargo, en adición a esta materia mito-simbólica, en la poesía del joven Yeats emergen también significados políticos más o menos explícitos, que me conducen a realizar una lectura de las implicaciones histórico-políticas postcoloniales de un texto que ha sido considerado más desde su concepción simbólica (Vincent, 1989; Khalifa, 2003).

El argumento de Las errancias de Oisin consiste en un diálogo entre San Patricio (c. 385 - c. 461), evangelizador y patrono de Irlanda, y Oisin -también conocido como Ossian, héroe y poeta legendario céltico, hijo de Finn-, en el que este último le relata al Santo su viaje por el Otro mundo precristiano, elogiando los valores paganos que allí ha vivenciado. Como parte del relato, Oisin recuenta el viaje a caballo que emprendió a través del mar a instancias de Niamh, hija de Aengus y princesa de las hadas, que se ha enamorado de su poesía. Niamh lo conduce a la isla de los Inmortales en la que viven juntos por cien años, hasta que Oisin siente nostalgia de sus compañeros de guerra fenianos. Entonces Niamh lo lleva a otra isla, donde habita Manannan, dios del mar y en la que Oisin se empeña inútilmente durante otros cien años en liberar a una mujer cautiva por un demonio. Luego se dirigirán a una isla en la que dormirán y soñarán por cien años más junto a los antiguos gigantes que la habitan. Es entonces que prima el deseo de Oisin de regresar a Irlanda, donde confronta la realidad de que sus compañeros de batalla han muerto y de que su isla ha sido convertida al cristianismo por San Patricio. Ante esta constatación, Oisin siente todo el peso de su vida en el tiempo suspendido de los inmortales y recupera demoledoramente su edad real de trescientos años.

Las errancias de Oisin propone así un viaje simultáneo a través del tiempo y del espacio. En el ámbito temporal, aunque los trescientos años de peregrinaje mítico de Oisin concluyen en el texto del poema con el triunfo de la evangelización de Irlanda, debe anotarse otra periodicidad, esta de carácter extratextual, que conduciría a hacer visible una recepción política del texto mítico. Me refiero a que, precisamente tres siglos antes de que Yeats escribiera el poema, tras la guerra de 1599-1602, Irlanda quedó finalmente sometida a la soberanía escocesa-inglesa (Sullivan, 1900: s. p.). Esta doble temporalidad intertextual/extratextual insinuaría a un tiempo un paralelismo entre la resistencia irlandesa hacia la dominación cristiana y la interpuesta contra el dominio colonial británico. En lo que refiere a lo espacial, el peregrinar de Oisin por diversas islas tiene profundas raíces en las antiguas tradiciones irlandesas, que pueden remontarse por lo menos hasta el viaje de San Brendan (Unterecker, 1959: 54). ${ }^{11}$ Debido entonces a su filiación a la tradición de la literatura de viajes, el mar -como afirma Guy Vincent- prima como el escenario principal en Las errancias de Oisin:

\footnotetext{
${ }^{11}$ Se sabe de múltiples versiones de El viaje de San Brendan (Navigatio Brendani), escrito en el siglo VIII siendo Navigatio sancti Brendani, texto del siglo IX, la más antigua versión conocida. De esta última, la copia manuscrita más antigua conservada actualmente data del siglo X (Alonso Navarro, 2012: 42). En esta misma tradición de peregrinajes espirituales que tienen lugar en escenarios marinos e insulares, cabría mencionar $E l$ purgatorio de San Patricio (Tractatus de Purgatorio Sancti Patricii), texto latino en prosa del siglo XII que contó con otras muchas versiones (Alonso Navarro, 2012: 172). Será necesario considerar, entonces, las relaciones entre los viajes de San Patricio -uno de los protagonistas el mismo de Las errancias de Oisin- San Brendan y del propio Oisin, en el contexto de la reescritura de las literaturas de viaje. Ambos textos continuaban siendo muy populares en el siglo XII. Agradezco la identificación de estas relaciones entre las historias de San Brendan y San Patricio al par evaluador que leyó generosamente mi propuesta de artículo para el monográfico "Islas imaginadas".
} 
Si Coleridge et Yeats choisissent la mer comme moyen physique de traduire une recherche, cela s'explique par ce besoin d'un espace qualifié et semblable au Lieu, étant donné que traditionnellement l'air renvoie trop au monde de l'idéalisme (et de la Raison) et la terre au matérialisme (et à l'illusion). L'espace marin se compose et se décompose en des figures qui sont autant de signes ou de lettres d'un alphabet inconnu (Vincent, 1989: s. p.).

Aunque el mar forma parte de la naturaleza habitual en que se inscribe Oisin, el viaje marino como tal no se manifiesta en el poema hasta la aparición de Niamh, que invita a Oisin a viajar con ella a su "[...] país [que] está muy lejos/allende el retumbar de esta marea" (Yeats, 2010: 29). ${ }^{12}$ Hasta este momento, el texto aún no precisa la categoría geográfica de este territorio de prodigios y bienaventuranza al que Oisin es invitado, sólo refiere que se llega a él a través del mar. El paraíso ultramarino donde habita Niamh es un universo de suaves mareas, de completa lealtad, donde la ausencia de tumbas delata la condición inmortal de sus habitantes. Constituye entonces un país de inmortales, una isla de los bienaventurados, donde corren el aceite, el vino, la miel y la leche, como en tierra de abundancia. ${ }^{13}$ Sin embargo, un hecho armado devuelve a los amantes a la realidad y da por terminada su estancia en la isla de los inmortales y con ella del Libro I.

El Libro II se corresponde con el próximo punto de llegada de Niamh y Oisin: la "Isla de los Muchos Horrores" (Yeats, 2010: 51). ${ }^{14}$ Se trata de un mundo insular en el que habita Manannan, dios celta del mar y la fertilidad, y guardián de las Islas de los Bienaventurados. ${ }^{15}$ La Isla está también poblada de demonios que se mantienen en guerra contra los hombres. Randy Williamson ha llamado la atención acerca de ese notable contraste entre el país de la juventud que han abandonado y esta "Isla de los Muchos Horrores" (1993: 145). Mientas que Richard Ellmann -en la misma dirección de enunciación del discurso histórico que propongo- apunta que esta segunda isla representaría a Inglaterra (Cit. en. Unterecker, 1959: 49). ${ }^{16}$ Esto me lleva a observar cómo en esta segunda isla visitada por Oisin se retoma un elemento histórico que contrasta con lo mítico:

En medio del trueno oigo

los caballos fenianos; quebradas armaduras;

risa y gritos. Las huestes chocan y se baten, y ahora se juntan los cuervos que oscurecen el día.

¡Detente, detente, oh lúgubre, risueño, cuerno feniano! (Yeats, 2010: 61) ${ }^{17}$

\footnotetext{
12 "[...] and my country far beyond the tumbling of this tide" (Yeats, 2010: 29). Vincent considera que la invitación de Niamh a Oisin conducirá al héroe de "[...] le monde humain pour l'Au-Delà imaginaire" (Vincent, 1989: s.p.).

${ }^{13}[\ldots]$ Mauricio Aguilera Linde afirma que la representación de esta primera isla "....is in fact a recreation of the Romantic vision of Nature secluded from the social pressures of the civilized world; a first version of Yeats's poetic fairyland whose inhabitants -the Immortals- do not know the meaning of words like Time, Death or Sorrow [...]" (Aguilera Linde, 1994: 12). Este mundo más allá de las tierras de los humanos es la isla en la que habita la gente del dios Danu: "In Irish-Celtic mythology, the Tuatha Dé Danann ('People of the goddess Danu') are the Irish race of gods, founded by the goddess Danu. These gods, who originally lived on 'the islands in the west', had perfected the use of magic. They traveled on a big cloud to the land that later would be called Ireland and settled there" (Lindemans, 2017: s. p.).

14 "The Isle of Many Fears" (Yeats, 2010: 50).

${ }^{15}$ Manannán mac Lir, que en celta significa "hijo del mar" es el dios irlandés del mar (“Manannán mac Lir”: s. p.)

${ }^{16}$ La crítica ha referido también que el Libro II de Las errancias de Oisin se basa en el episodio de Glauco en el libro III del "Endymion" de John Keats (1795-1821), autor este último que hacía parte de las lecturas y estudios de Yeats. Ambos poemas acontecen también en un ambiente marino (Williamson, 1993: 144). En igual dirección, Vincent afirma que: "Les modèles de Yeats seraient à trouver chez les écrivains anglais romantiques uniquement: Blake, Wordsworth, Coleridge, Keats ... déniant à Yeats toute identité irlandaise" (Vincent, 1989: s. p.)

17 "I hear amid the thunder / The Fenian horses; armour torn asunder; / Laughter and cries. The armies clash and shock, / And now the daylight-darkening ravens flock. / Cease, cease, O mournful, laughing Fenian horn! (Yeats 2010: 60).
} 
La reaparición de la imagen de los guerreros fenianos en esta batalla devuelve el poema a la ambigüedad temporal que he señalado antes. El gentilicio "fenianos" ("fenians") refiere a: 1.) los miembros de una banda armada legendaria que defendía a Irlanda en los siglos II y III A. C., época de la materia de Las errancias de Oisin ("Fianna": s.p.); y 2.) a los integrantes de una organización secreta del siglo XIX, dedicada a combatir el poder británico en Irlanda ("Fenian": s.p.). Desde los años ' 80 del siglo XIX, Yeats demostró amplias simpatías con las distintas organizaciones que conformarían el fenianismo. Autores como Birgit Bramsbäck insisten en que: "It is well known that W. B. Yeats used Fenian or Ossianic material in his long poetic work, The Wanderings of Oisin..." (Bramsbäck, 1999: 3). A esto cabe agregar, desde la perspectiva de género asumida por Marjorie Elizabeth Howes, cómo Yeats establece en el poema una contradicción cultural entre feminidad y masculinidad, en la que los fenianos, prominentemente masculinos, representarían el nacionalismo irlandés, mientras que la Irlanda cristiana, asociada a Saint Patrick, contrastaría por su ausencia de virilidad (Howes, 1996: 28).

El Libro II concluye, tras esta peripecia imaginaria, si cabe decir, que confronta nuevamente a Oisin con el recuerdo de sus amigos. De ese modo, se repite la misma estrategia narrativa que da final al Libro I: la reminiscencia de la guerra y de sus amigos guerreros. Estas peripecias no constituyen sucesos "reales" o verdaderos actos de guerra característicos de la epopeya o de narraciones de viaje. Son sólo recuerdos, remembranzas, memorias, elucubraciones mentales que confrontan al héroe con su pasado guerrero y que lo compelen al viaje, a continuar su peregrinaje insular:

\author{
Y entonces murmuró la perdida Niamh: “Amor, \\ Vamos a la Isla del Olvido, iporque mira! \\ Las Islas del Baile y las Victorias \\ Carecen de poder". \\ “Y cuál de éstas \\ es la isla del Contento?" \\ "Nadie lo sabe", dijo, \\ Poniendo su cabeza llorosa en mi regazo (Yeats, 2010: 63, 65). ${ }^{18}$
}

Niamh juega aquí un importante papel en la catalización de ese desplazamiento. Cada huida de una de las islas coincide con otro de sus intentos de sustraer a Oisin del dilema de la historicidad heroica que lo constituye, para que alcance a sumergirse en el letargo imperturbable que el amor

\footnotetext{
18 "And then lost Niamh murmured, 'Love, we go / To the Island of Forgetfulness, for lo! / The Islands of Dancing and of Victories/Are empty of all power.' / 'And which of these / Is the Island of Content?'/ 'None know,' she said; / And on my bosom laid her weeping head”' (Yeats, 2010: 62, 64).
} 
inmortal de ella le procura. El papel de Niamh en la propiciación del viaje insular contrasta con las funciones retardatorias de este que juegan las figuras femeninas en la Odisea de Homero. Seres mortales o inmortales, benignos o malignos -Nausica como mujer mortal, la maga Circe, la ninfa Calipso, las criaturas monstruosas Escila y Caribdis, las propias Sirenas (Aguirre, 1999)- se proponen retener sentimentalmente a Odiseo en cada uno de sus territorios insulares, interponiéndosele en su regreso a casa y con ello prolongando la aventura, obstaculizando la conclusión de la hazaña, y otorgándole mayor densidad y duración a la narración epopéyica de la novela de viaje. No puedo evitar la tentación de incluir a Espirta, la madre de Abdala, en esta lista de seres femeninos que se proponen retardar la partida, el inicio del viaje y el cumplimiento del destino del héroe guerrero.

Sin embargo, no hay aquí una real contraposición pues, ya sea que retarden o inciten al viaje, tanto Niamh, Espirta, como las figuras femeninas de la Odisea, coinciden en la función narrativa de generar peripecias que dificulten la materialización del destino del héroe. De proponer un verdadero antagonismo femenino, en el terreno intertextual del viaje insular en la Odisea y Las errancias de Oisin, tendríamos que apelar a las figuras de Atenea y Niamh. ${ }^{19}$ Mientras la Atenea homérica acompaña a Odiseo en la multitud de sus viajes, auxiliándolo para que escape a la imantación paralizadora de las islas y concrete así su destino heroico, Niamh se propone llevar a Oisin de su mano de isla en isla, de modo que este olvide su condición de guerrero y renuncie a concretar lo que él considera su misión heroica. A pesar de su distinta genealogía mítica, creo ver en la actuación de Atenea y Niamh en relación con Odiseo y Oisin respectivamente, una encarnación del dilema del héroe que se debate entre su condición mortal y la agencialidad de su destino humano, por un lado, y la impasibilidad y desapego de las entidades inmortales.

Atendiendo a otro aspecto central del fragmento citado, es necesario referir que ha habido varias interpretaciones acerca de los significados implícitos de las islas que se mencionan en este -Isla del Olvido, Islas del Baile y las Victorias, y la Isla del Contento- sin que haya total acuerdo al respecto (Aguilera Linde, 1994; Reynaud-Pei, 2017). Subsiste entonces la pregunta acerca de cuáles serán entonces las Islas del Baile y las Victorias. ¿Acaso se corresponde con la isla de los inmortales (Libro I)? Seguramente no alude a la "Isla de los muchos miedos" (Libro II). ¿Acaso a la Isla del olvido (Libro III)? Puede sin embargo afirmarse que la Isla del Olvido es un espacio de reencuentro de Oisin con la realidad de su presente, aunque no deja de presentar un territorio insular que corresponde con una arquetipología occidental ya establecida:

En las islas de los mares más remotos, adonde sólo los espíritus llegan.

¿No eran los vientos más suaves que el aliento de una paloma que duerme en su nido,

\footnotetext{
${ }^{19}$ Para otros tratamientos de la figura de Atenea en la obra de Yeats véase Kaplan, 1971: 148-149, 200.
} 
o perdido en los fuegos de llamas y aromas el sonido del vago

tambor del mar?

Oh flamante león del universo, oh, ¿cuándo volverás al reposo?” (Yeats, 2010: 79). ${ }^{20}$

La ubicación remota de las islas remite a un exotismo de índole orientalista, las reafirma como un espacio trascendente, no terreno, al que sólo tienen acceso los seres inmortales. Son islas simbólicas, aunque no necesariamente asociadas a un contenido mítico. A este nuevo territorio lo acompaña el torturante recuerdo de los héroes fenianos desaparecidos. Este sentimiento se agudiza y lo conduce a Oisin al grito. Los viejos héroes han desaparecido, quizás para el poeta ya sea hora de que aparezcan nuevos héroes. Con ellos también han huido las islas, que se revelan ahora como el contenido de un sueño ido: "[...] y se habían desvanecido los sueños de las islas, y supe cómo / los hombres sufren y desaparecen, / y su perro, y su caballo, y su amor, y sus ojos que brillan / tenuemente como seda" (Yeats, 2010: 83). ${ }^{21}$

Como plantea Philip Steinberg, la propia condición geográfica de las islas, su aislamiento, pareciera evocar simbólicamente la posibilidad de la independencia nacional, su no hacer parte de otro mundo que del océano: “[...] as Philip Steinberg has shown, island geography has anticipated the 'idea of the sovereign territorial state', furnishing in elemental form a pictorial equivalent of the 'state ideal' of homogeneous, sharply demarcated, and singular geopolitical entities, and encouraging the naturalizing conflation of political and geographical boundaries [...]" (cit. en Balasopoulos, 2008: 11). Los fenianos, defensores de la antigua Irlanda, ya no están para preservar esa condición insular signo de la libertad y la independencia. No sobrevive una posibilidad para la existencia para las islas. El Libro III cierra entonces con la pérdida de posibilidad tanto de los héroes como de las islas mismas.

Khalifa ha reiterado que: "With the Wandering of Oisin, Yeats starts to ground his poetic text in the mainstream of Irish immediate political and historical reality" (2003: s.p.). Correspondientemente con esa dimensión histórico-política, en su intento de recuperar un pasado y una tradición no restituibles, Las errancias de Oisin se correspondería con esa forma paradigmática del poema poscolonial enunciada por Ramazani: "The postcolonial poem, like a postcard, risks miniaturizing, idealizing, and ultimately displacing the remembered native landscape" (2001: 12). Este desplazamiento del paisaje propio, representaría así la intención de poetas postcoloniales de rescatar " $[. .$.$] the precolonial past as a power-$ ful locus of identity, yet self-consciously probe the multiplicity and constructedness of the home they dislocate in the moment of reinhabiting it" (Ramazani, 2001: 13).

\footnotetext{
20 'In the isles of the farthest seas where only the spirits / come. / Were the winds less soft than the breath of a pigeon who / sleeps on her nest, / Nor lost in the star-fires and odours the sound of the sea's / vague drum? / O flaming lion of the world, O when will you turn to your / rest?' (Yeats, 2010: 78).

21 " [...] dreams of the islands were gone, and I knew how men sorrow and pass, / And their hound, and their horse, and their love, and their eyes that glimmer like silk" (Yeats, 2010: 82).
}

\section{4}

VISITAS AL PATIO Vol.13, No.2: 42-59, 2019 
Adicionalmente, a la vez que una recuperación del "locus de la identidad", Ramazani identifica en otro de sus trabajos que: "[...] Yeats's hybridization of geographies should not be seen as idle cosmopolitanism: it represents, at least in part, a reverse colonization, the world-gathering gesture of a poet whose country has been occupied for centuries and whose culture has been threatened with extinction. 'Out of Ireland' Yeats comes, imaginatively repossessing the island and annexing vast territories beyond" (Ramazani, 1998: 83). Los hombres que bajan de la montaña al final del poema, símbolo de lo alto y lo sagrado, cargan con el último rastro del mar, un saco agujereado de arenas marinas que ha de servirles como homenaje a los viejos guerreros muertos. Luego sólo queda Oisin, devenido un anciano decrépito, tras el disuelto efecto mágico de los espacios insulares, que representan un viejo orden social, religioso y simbólico, al parecer, imposible de restablecer.

\section{Islas globales e imaginarios (pos)coloniales: desplazamientos espaciales y disciplinares}

Si en "Abdala", de José Martí, se produce un desplazamiento espacial, en el que se traslada el escenario de su representación de la isla caribeña a una nación africana, en Las errancias de Oisin, de W. B. Yeats, el desplazamiento tiene lugar en el eje temporal, remontándose a los orígenes míticos de la nación irlandesa. Tanto "Abdala" como Las errancias de Oisin dan cuenta de desplazamientos espaciales y temporales postcoloniales que funcionan como estrategias para burlar la vigilancia y control colonial representacional de sus respectivas metrópolis.

Al menos en la experiencia de Yeats funcionaría el aserto de Said: "Because of the presence of the colonizing outsider, the land is recoverable at first only through the imagination" (1996: 225), lo que da cuenta, en palabras de Khalifa, del tránsito de Yeats “[...] from the rhetoric of universalism to the politics of particularism" (2003: s.p.). Pero en "Abdala" -de forma contraria a la recuperación imaginaria del espacio-tiempo en que hemos visto enfrascarse a Yeats en Las errancias de Oisinla estrategia política independentista aconseja a Martí renunciar a la representación imaginaria del espacio insular, constitutivo de la isla de Cuba, llevándolo a optar por la configuración de un reino africano continental de ambiguos significados para sus contemporáneos, en pro de poder combatir, subrepticiamente, por la independencia política real de la nación cubana.

El análisis comparado de "Abdala" y Las errancias de Oisin revela la insistencia de estos textos en adoptar estrategias de representación de territorios insulares, empleando formas altamente significativas de desplazamiento del espacio y el tiempo poscolonial. Estos desplazamientos apuntan a una espacialidad translingüística, transatlántica y transimperial, que privilegia la configuración de relatos acerca de las experiencias de comunidades insulares tempranamente globalizadas, como consecuencia de las condiciones coloniales a las que han estado sujetas. Dichas interconexiones insulares a escala global, al escapar a los esquemas disciplinarios actuales de los estudios literarios, demandan nuevos desarrollos transdisciplinarios que, desde los estudios literarios insulares, avancen en la construcción de conocimientos decoloniales acerca y desde la posicionalidad de las islas y los sujetos insulares. 


\section{BIBLIOGRAFÍA}

Aguilera Linde, M. (1994). Oisin's Quest: The Myth of the Modernist Poet's Evolution. Revista Alicantina de Estudios Ingleses, (7), 7-22. Repositorio Institucional de la Universidad de Alicante (RUA). Recuperado de https://rua.ua.es/dspace/bitstream/10045/6011/1/ RAEI_07_01.pdf

Aguirre, M. (1999). Presencia femenina en la travesía de Odiseo: estudio iconográfico. Espacio, tiempo y forma, Serie II, Historia antigua, t. 12, 87-105. Recuperado de http://revistas.uned. es/index.php/ETFII/article/download/4348/4187

Alonso Navarro, J. A. (2012). Estudio de los topoi en el poema irlandés "La visión de Tundal" y en los poemas ingleses "El purgatorio de San Patricio" o "Sir Owain" y "El espíritu de guy" en el marco de la literatura inglesa e irlandesa de visión del cielo, infierno y purgatorio de los siglos VIII al XV (Tesis de doctorado). Universidade da Coruña, Coruña/Ferrol. Repositorio Universidade Coruña (RUC). Recuperado de https://ruc.udc.es/dspace/bitstream/handle/2183/10066/AlonsoNavarro_JoseAntonio_TD_2012.pdf?sequence=3\&isAllowed=y

Azougarh, A. (1998). Martí orientalista. Casa de las Américas, (210), 12-20.

Balasopoulos, A. (2008). Nesologies: Island Form and Postcolonial Geopoetics. Postcolonial Studies, 11(1), 9-26.

Baldacchino, G. (2006). Island, Island Studies, Island Studies Journal. Island Studies Journal, 1(1), 3-18. Recuperado de https://www.islandstudies.ca/sites/vre2.upei.ca.islandstudies.ca/ files/u2/ISJ-1-1-2006-Baldacchino-pp3-18.pdf

Bramsbäck, B. (1999). Fenian Material in the Work of James Stephens. Celtica, (23) 3-18. Recuperado de https:/www.dias.ie/wp-content/uploads/webstore/celt/pubs/celtica/c23/ c23-3.pdf

Campomanes, O. (2018). The Islandic in the Postcolonial Critique of American Empire. University of California Humanities Research Institute (UCHRI). Recuperado de https://uchri.org/ foundry/the-islandic-in-the-postcolonial-critique-of-american-empire/

Carruthers, G. (2003). Introduction: romancing the Celt. En G. Carruthers (Ed.). English Romanticism and the Celtic World (pp. 1- 19). West Nyack, NY, USA: Cambridge University Press. Ebrary.

Cowell, R. (1969). Dreams of Ireland. En W. B. Yeats (Literature in perspective) (pp. 11-36). London: Evans, 1976. 
Depraetere, C. (1990-1991). "Le phénomène insulaire á l'échelle du globe: tailles, hiérarchies et formes des îles océanes”. L'Éspace Géographique, (2), 126-134.

Depraetere, C. (2008). The Challenge of Nissology: A Global Outlook on the World Archipelago. Part I. Scene Setting the World Archipelago. Island Studies Journal, 3(1), 3-16. Recuperado de https://www.islandstudies.ca/sites/vre2.upei.ca.islandstudies.ca/files/ISJ-3-1-2008-Depraetere1-FINAL_0.pdf

Ette, O. (1986). Apuntes para una orestiada americana: José Martí y el diálogo intercultural entre Europa y América Latina. Revista de Crítica Literaria Latinoamericana, 12(24), 137-146.

Fenian (2019). Wikihand. Recuperado de: https://www.wikiwand.com/en/Fianna

Fianna (2018). Wikihand. Recuperado de: https://www.wikiwand.com/en/Fianna

Gutiérrez de la Solana, A. (1978). José Martí: prefiguración de su vida en Abdala y Patria y libertad. Latin American Theatre Review, 11(2), [17]-23. https://journals.ku.edu/index.php/latr/ article/viewFile/310/285

Hay, P. (2006). A Phenomenology of Islands". Island Studies Journal, 1(1), 19-42. Recuperado de https://www.islandstudies.ca/sites/vre2.upei.ca.islandstudies.ca/files/u2/ISJ-1-1-2006-Haypp19-42.pdf

Howes, M. E. (1996). Yeats's Nations: Gender, Class, and Irishness. Cambridge: Cambridge University Press.

Kaplan, G. (1971). The Image of Woman in the Poetry of W. B. Yeats (1865-1939). (Tesis de maestría). University of Cape Town, Cape Town. Recuperado de https://open.uct.ac.za/bitstream/item/21068/thesis_hum_1972_kaplan_gloria.pdf?

Khalifa, R. (2003). The Rhetoric of Transition or Political Allegoria in the Young Yeats. Agenda Poetry. Recuperado de http://www.agendapoetry.co.uk/documents/RachedKhalifa-TheRhetoric.pdf

Lindemans, M. F. (2017). Tuatha Dé Danann. 1997. The Willow Series. Celtic Mythology. Recuperado de http://www.the-willow-series.com/celtic-mythology.html

Manannan mac Lir (2019). Encyclopcedia Britannica. Recuperado de https://www.britannica. com/topic/Manannan-mac-Lir 
Martí, J. (2016). Abdala. La Patria Libre, (23), 1869. Obras completas. Ed. crítica. t. 1, (pp. 13-22). La Habana: Centro de Estudios Martianos; Buenos Aires: CLACSO. Red de Bibliotecas Virtuales de CLACSO. Recuperado de http://biblioteca.clacso.edu.ar/clacso/ se/20160824043346/JOSE-MARTI_Tomo-01.pdf

McCall, G. (1994). Nissology: A Proposal for Consideration. Journal of the Pacific Society, 17(23), 1-8.

Mignolo, W. (1995). Afterword: Human Understanding and (Latin) American Interests--The Politics and Sensibilities of Geocultural Locations. Poetics Today, 16(1), 171-214. JSTOR. Recuperado de http://www.jstor.org/stable/1773227

Mignolo, W. (1998). Postoccidentalismo: el argumento desde América Latina. En S. CastroGómez y E. Mendieta (Eds.). Teorías sin disciplina: Latinoamericanismo, poscolonialidad y globalización a debate. México: Miguel Ángel Porrúa. Recuperado de https://www. ensayistas.org/critica/teoria/castro/mignolo.htm

Moles, A. (1982). Nissonologie, ou Science des Îles. L'Éspace Géographique, (4), 281-289.

Poumier, M. (1992). Abúfar-Abdala. Aspects tragiques de la cubanité 1820-1880. Paris : Publications de l'équipe de Recherche de l'Université de Paris VIII.

Ramazani, J. (1998). Is Yeats a Postcolonial Poet?. Raritan, 17(3), 64-89. ProQuest Central.

Ramazani, J. (2001). The Hybrid Muse: Postcolonial Poetry in English. Chicago: University of Chicago Press.

Said, E. (1996). Yeats y la descolonización. En: Cultura e imperialismo (pp. 342-369). 1993. Trad. Nora Catelli. Barcelona: Anagrama.

Sedeño-Guillén, K. (2019). “Introducción: Islas (des)imaginadas: de la matriz moderno-colonial al Caribe archipelágico". Visitas al Patio, (14), 10-21.

Shell, M. (2014). Islandology: Geography, Rhetoric, Politics. Stanford, CA: Stanford University Press.

Suárez León, C. (2004). Traducir y transgredir: Heredia como modelador de la cultura cubana. HISTAL. Recuperado de: http://www.histal.net/wp-content/uploads/2011/08/ Traducir-y-transgredir-Heredia-como-modelador.pdf

Sullivan, A. M. (1900). Chapter LIII. Story of Ireland: Being a Complete and Authentic History of 
Ireland from the Earliest Ages to 1867. En: Atlas and Cyclopedia of Ireland. Part II. New York: Murphy \& McCarthy. Internet Archive. Recuperado de https://archive.org/details/atlascyclopediao02joyc/page/n10

Reynaud-Pei, S. (2017). W.B. Yeats and the Good People: The Celtic Influence in Yeats's Early Works (1885-1900). (Tesis de maestría). Université de Nice Sophia-Antipolis, Niza. Recuperado de https://www.academia.edu/36789760/Yeats_and_the_Good_People_The_ Celtic_influence_in_Yeats_s_early_works_1885-1900_

Unterecker, John (1959). The Wanderings of Oisin. A Reader's Guide to William Butler Yeats ([47]-66). New York: Noonday Press.

Vincent, Guy (1989). Dérades. París: Editions Carâcara. Recuperado de http://www.utqueant.org/ net/der0.html

Yeats, William Butler (2010). Las errancias de Oisin. En Poesía reunida (pp. [22]-89). Trad. Antonio Rivero Taravillo. Valencia: Pre-Textos.

Williamson, Randy (1993). Keats and Oisin: A Study in Narrative Technique. Artes liberales (53), 139-146. Recuperado de http://id.nii.ac.jp/1399/00013504/ 